Research Article

\title{
The Influence of Salt Solution on Morphological Changes in a Geosynthetic Clay Liner
}

\author{
Mochamad Arief Budihardjo \\ Department of Environmental Engineering, Diponegoro University, Semarang 50275, Indonesia \\ Correspondence should be addressed to Mochamad Arief Budihardjo; tl.diponegoro@gmail.com
}

Received 28 December 2015; Revised 26 April 2016; Accepted 28 April 2016

Academic Editor: Giorgio Pia

Copyright ( 2016 Mochamad Arief Budihardjo. This is an open access article distributed under the Creative Commons Attribution License, which permits unrestricted use, distribution, and reproduction in any medium, provided the original work is properly cited.

\begin{abstract}
Morphological variations of geosynthetic clay liner (GCL) samples, hydrated with two different permeates, distilled water and $\mathrm{NaCl}$ solution (100 mM concentration), were observed in detail using microscopic analysis. After the GCL samples were hydrated with the $\mathrm{NaCl}$ solution, they were observed with an optical microscope. While the surface of the treated GCL samples was similar to the surface of the untreated GCL, a crystal deposit was found on the surface of the treated samples. Using a scanning electron microscope (SEM), a more solid appearance was observed for the bentonite particles contained in the GCL after the sample was hydrated with distilled water in comparison to the GCL sample that was hydrated with the $\mathrm{NaCl}$ solution. It appears that salt solution hydration results in less swelling of the bentonite particles. Furthermore, the energy-dispersive X-ray spectrometer (EDS) results showed that distilled water hydration had no effect on the distribution of the elements contained in the GCL samples. However, bound chlorine was observed, which demonstrated that the bentonite particles had absorbed the $\mathrm{NaCl}$ solution. In addition, changes in the hydraulic conductivity of the hydrated GCL samples were also observed.
\end{abstract}

\section{Introduction}

Landfilling still remains the most preferred solid waste disposal method globally [1-4]. In landfill, solid waste will start to decompose and generate leachate [5]. Leachate contains various organic and inorganic materials, pathogens, and heavy metals in various concentrations and is very challenging to manage [6-11]. Severe environmental and health hazards are possible if the leachate escapes from a landfill and contaminates the surroundings, such as the groundwater [1215]. Landfills must be able to function as a hydraulic barrier to prevent leaks or as a proper collection for the leachate [1621]. Thus, the most critical function of landfill design and construction is to contain leachate $[1,22]$, in order to reduce the environmental and public health impacts of a landfill.

In order to inhibit the environmental impact of landfill leachate, landfills are equipped with an impermeable bottom liner to prevent leachate contaminating the surrounding soil and groundwater [1,5]. According to Ludwig et al. [2], a common practice of landfill operators is to place an impermeable soil layer such as compacted clay liner (CCL) at the bottom of a landfill site to prohibit leachate infiltration.
However, in developed countries, a geosynthetic clay liner (GCL) has been used as a barrier for landfill leachate instead of compacted clay liner (CCL). The GCL has replaced CCL due to its greater benefits, such as availability, transport, handling, installation, and cost [23]. When GCL is manufactured it normally has two geosynthetic layers with bentonite in between which swells and becomes impermeable when hydrated. Generally, the permeability of the geosynthetic layers depends on some factors such as degree of hydration, temperature, permeant liquid [24-26], and also liner configuration, for instance, single liner or a composite liner with geomembrane [23, 27].

The degree of saturation determines GCL's capability of achieving maximum hydraulic performance. For GCL to impede the seepage of a liquid contaminant, the liner system should be sufficiently hydrated (normally with water) [27]. Hydration tends to cause the bentonite particles in the GCL to swell and attach to each other. Once the GCL is positioned above an underlying subgrade, like wet soil, the hydration process begins immediately. Due to the moisture content in the subgrade, there is no need to add water to the GCL. Water from the subgrade will be absorbed by the GCL to make it 


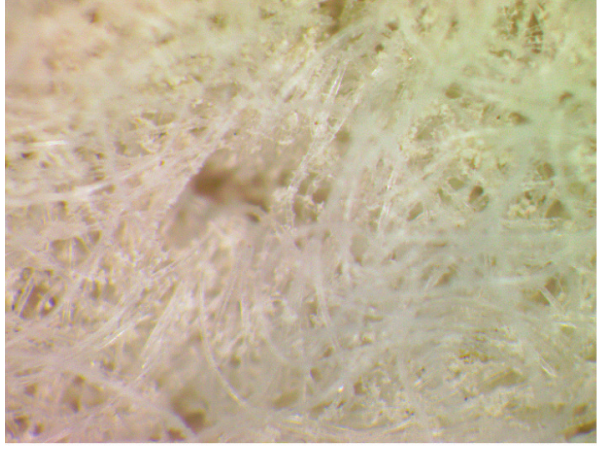

A-D

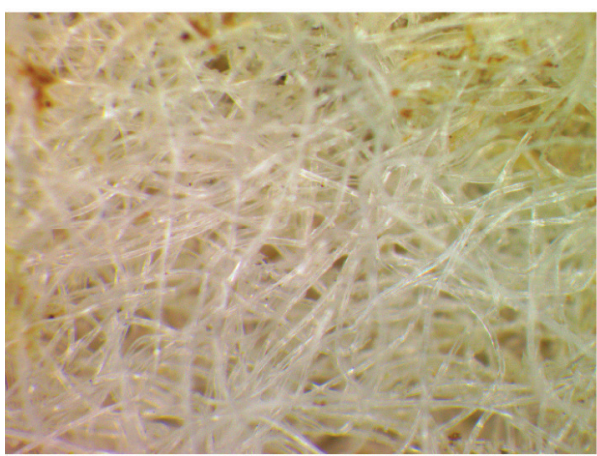

A-A

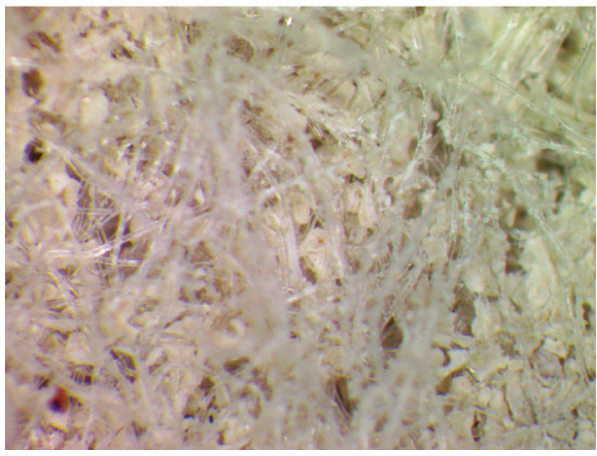

A-S

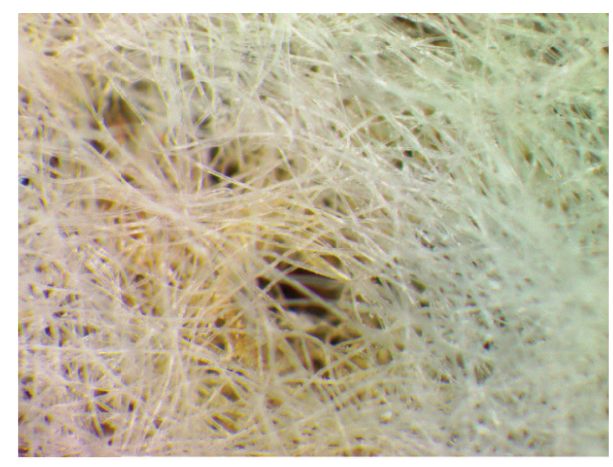

B-D

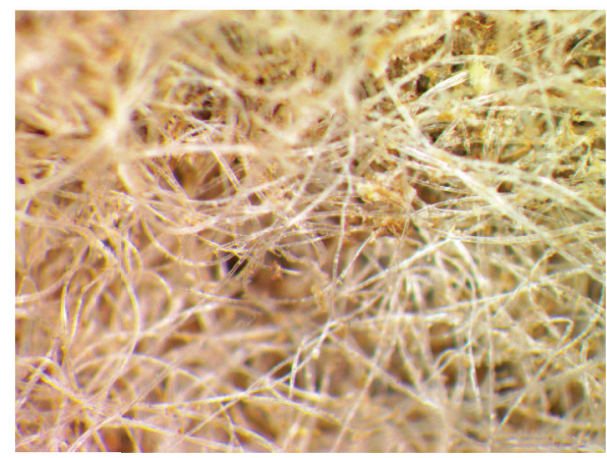

B-A

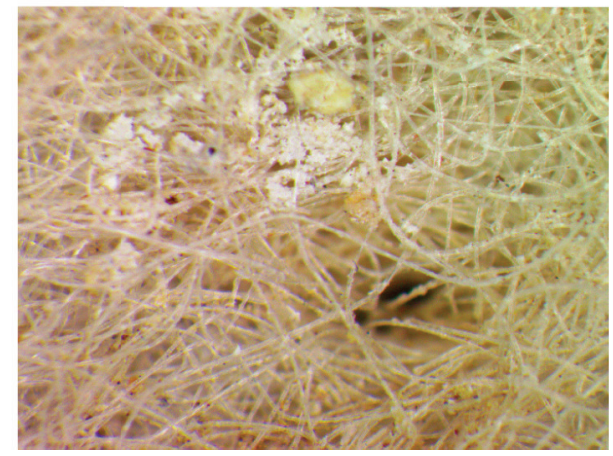

B-S

FIGURE 1: Microscopic view of the physical appearance of the GCL samples: A-D and B-D: initial condition of the GCL; A-A and B-A: GCLs after hydration using distilled water; A-S and B-S: GCLs after hydration using the $\mathrm{NaCl}$ solution.

swell and become impermeable to water during the hydration process. However, during its function as leachate barrier, the GCL also has to deal with leachate which may contain organic matter, heavy metals, and inorganic salts [28, 29].

Some studies have investigated the relationship between the seepage of inorganic salt solutions and GCL's hydraulic conductivity [28-31]. The permeability of GCL was found to vary when the solution contained a strong concentration of $\mathrm{NaCl}$ or a large portion of polyvalent cations. Moreover, when a weak concentration of the $\mathrm{NaCl}$ solution was used to permeate the GCL, similar hydraulic conductivity was found in comparison to permeation with deionised (DI) water or tap water [32]. Meanwhile, Jo et al. [32] indicated that long term permeation using $\mathrm{NaCl}$ solution with very strong concentration resulted in a threefold increase in the hydraulic conductivity of the GCLs.
As an extension of previous research findings, this present research aims to address the morphological changes in GCLs by conducting a partial level examination utilizing microscopic views, which provides a clearer demonstration of the influence that salt solution has on GCLs. In this study, $100 \mathrm{mM}$ of $\mathrm{NaCl}$ solution was used as the seepage fluid.

\section{Materials and Methods}

This experiment investigated two types of prepared GCL samples that were obtained from two different suppliers. Sodium bentonite was present in all the samples: the letter " $A$ " on the label was used to identify the bentonite powder samples while the letter " $\mathrm{B}$ " was used for the granular bentonite samples. Hydration NaCL solutions, with a concentration of $100 \mathrm{mM}$, were then prepared using distilled water and salt. 


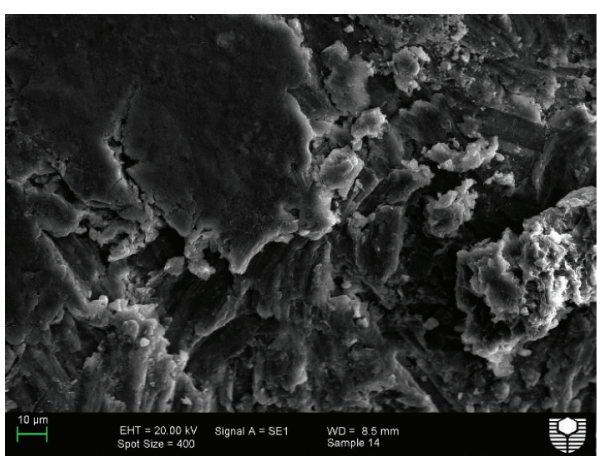

A-D

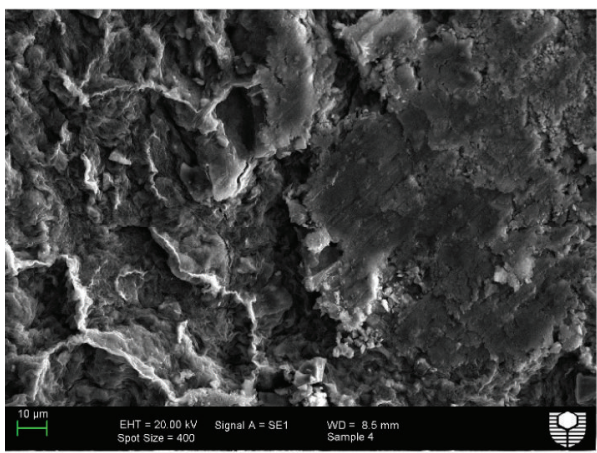

A-A

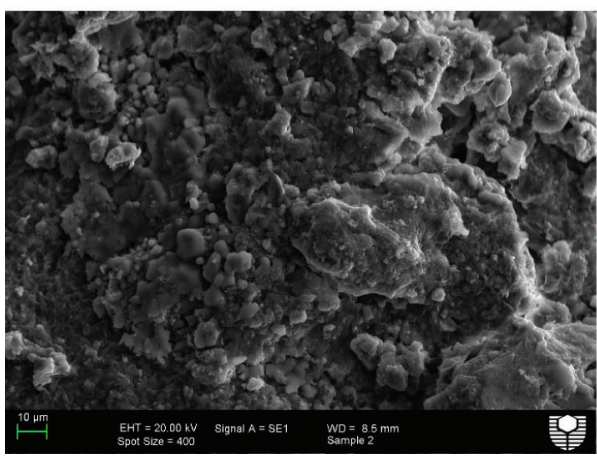

A-S

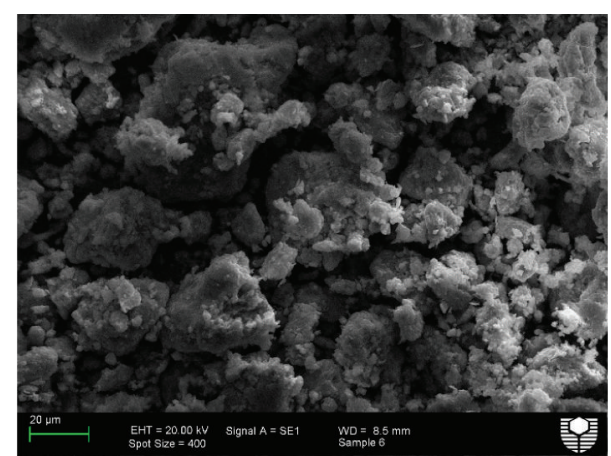

B-D

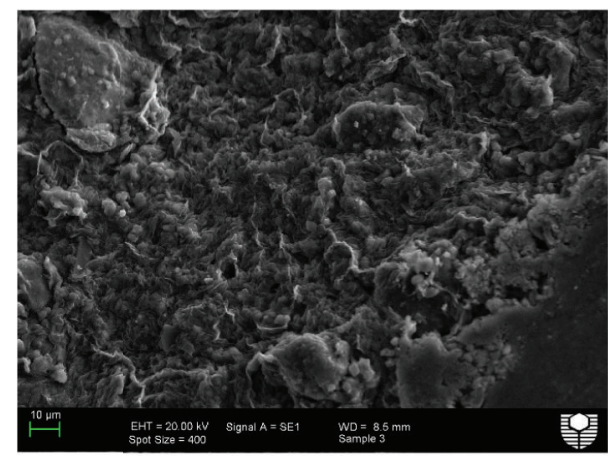

B-A

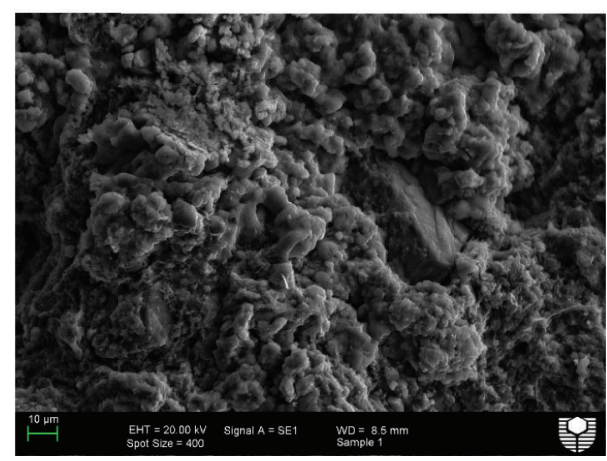

B-S

FIGURE 2: The SEM views of bentonite particles in the GCL samples under the following conditions: A-D and B-D: initial status before hydration; A-A and B-A: after hydration with distilled water; A-S and B-S: after hydration with the $\mathrm{NaCl}$ solution.

The second letter of the sample label indicated the sample condition. The original GCL samples (dry) were marked with a "D," while the samples labelled with "A" represented the GCL samples that were hydrated with distilled water and the samples labelled with " $\mathrm{S}$ " indicated hydration with the $\mathrm{NaCl}$ solution (Table 1).

As stated above, microscopic imaging was used to investigate the GCL samples. A scanning electron microscope (SEM) was used to examine the bentonite particles. Microscopic images of the GCL samples were produced utilizing a Nikon ME600 light microscope and analyzed with Top View, an image processing software for light microscopes. A Zeiss Evo 40 XVP was used to obtain the SEM images, and it could determine the elemental composition of the samples
TABLE 1: GCL sample codes.

\begin{tabular}{lcc}
\hline $\begin{array}{l}\text { Sample code for } \\
\text { microscopic images }\end{array}$ & Bentonite type & Hydration condition \\
\hline A-D & Powder & Dry \\
B-D & Granular & Dry \\
A-A & Powder & DI water \\
B-A & Granular & DI water \\
A-S & Powder & $\mathrm{NaCl}$ \\
B-S & Granular & $\mathrm{NaCl}$ \\
\hline
\end{tabular}

by connecting to an Oxford Instruments energy-dispersive Xray spectrometer (EDS). Equipped with INCA peak matching 


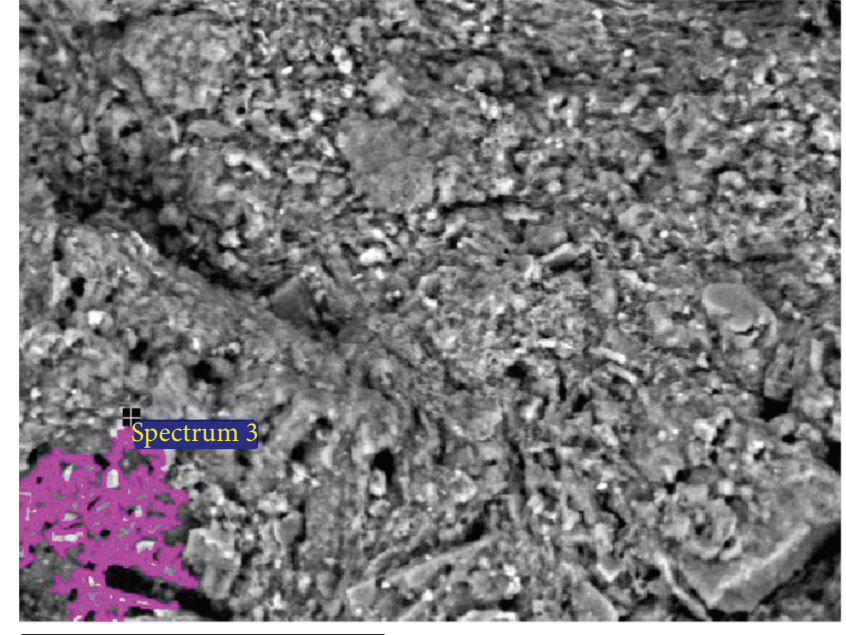

$100 \mu \mathrm{m}$

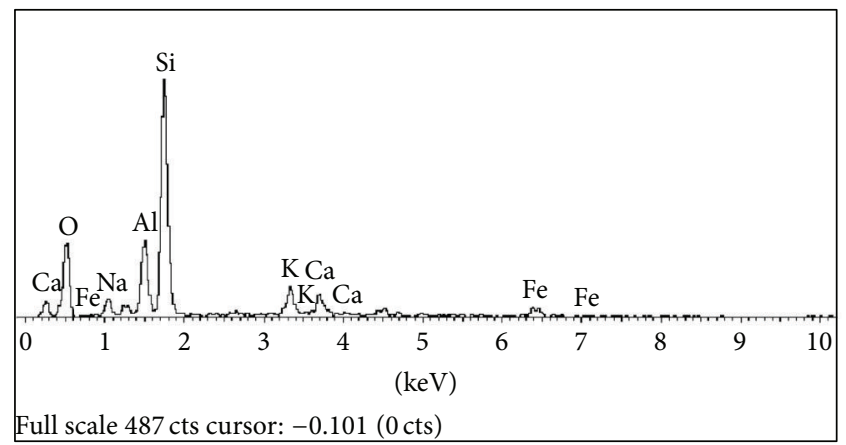

A-D

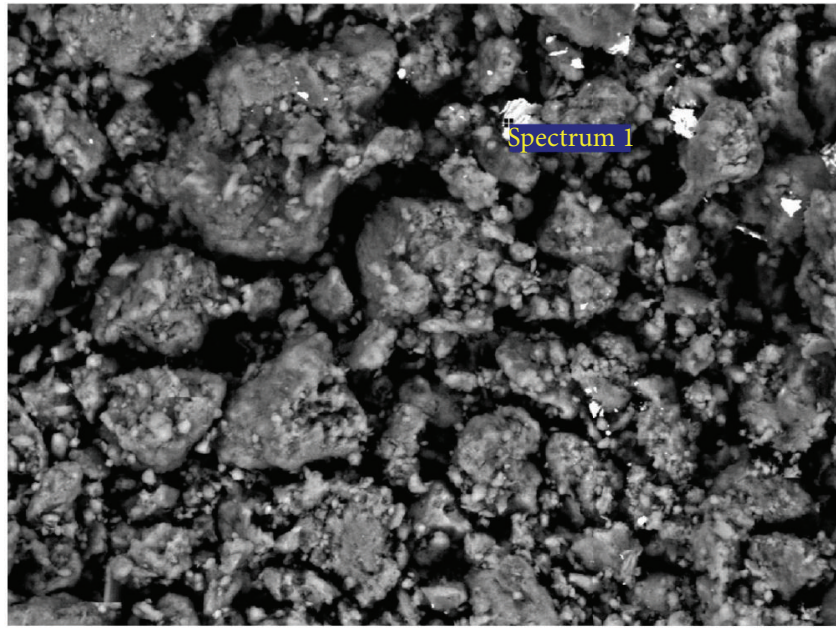

$100 \mu \mathrm{m}$

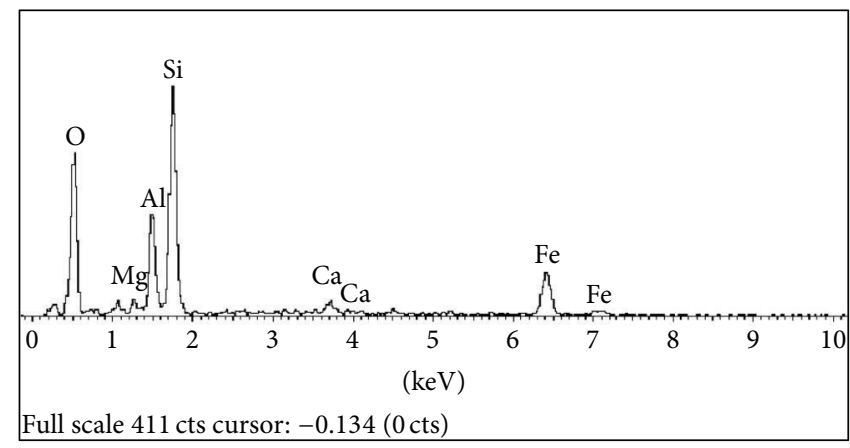

B-D

FIGURE 3: Elemental distribution images of samples A-D and B-D before hydration.

software, the EDS made it possible to more quickly identify the elements.

\section{Results and Discussion}

After two weeks of hydration, the moisture content in the GCL samples was removed by placing them in the oven. Optical microscopy was used to observe any physical changes both before and after hydration (Figure 1).

No differences were observed in the physical appearance of samples A-D, A-A, B-D, and B-A. This demonstrates that hydration with distilled water, followed by drying, had no effect on the form of the GCL sample as it remained unchanged under microscopic observation. However, some crystal deposits were found on the A-S and B-S samples on the top of the bentonite layer and attached to the geosynthetic cover; the crystal deposits were the dry form of $\mathrm{NaCl}$.

3.1. SEM and EDS. The GCL samples were then examined using a scanning electron microscope (SEM) to determine the morphological and mineralogical characterizations of the specimens. An SEM can show the binding characteristics of the liner membrane, and it was used to observe the physical changes in the interparticle interactions due to hydration with different solutions. The morphology of the investigated GCL samples is shown in Figure 2, which illustrates the images of the GCL particles both before and after hydration using distilled water and the $\mathrm{NaCl}$ solution.

As seen in Figure 2, the images of samples A-D and B$D$ represent the raw form of bentonite before being hydrated with any type of solution. Sample A-D was the powder form of bentonite and sample B-D was the granular form. A comparison of the images for $\mathrm{A}-\mathrm{D}$ and $\mathrm{B}-\mathrm{D}$ shows that the surface morphology of the bentonite particles varied between the powdered and granular forms. Analysis of the SEM images showed that the particle clods in the bentonite powder were larger and denser than the granular bentonite particles.

A comparison of A-A and B-A revealed that distilled water hydration led to the flocculation of the particle clods resulting in the formation of a more solid bentonite surface appearance as well as a tighter attachment between the particles. Therefore, it can be stated that (1) the hydration of bentonite with distilled water has a significant influence on the bentonite particles rather than the structure and crystallography of the particles and (2) bentonite hydration with distilled water tends to reduce the interparticle spaces or voids. 


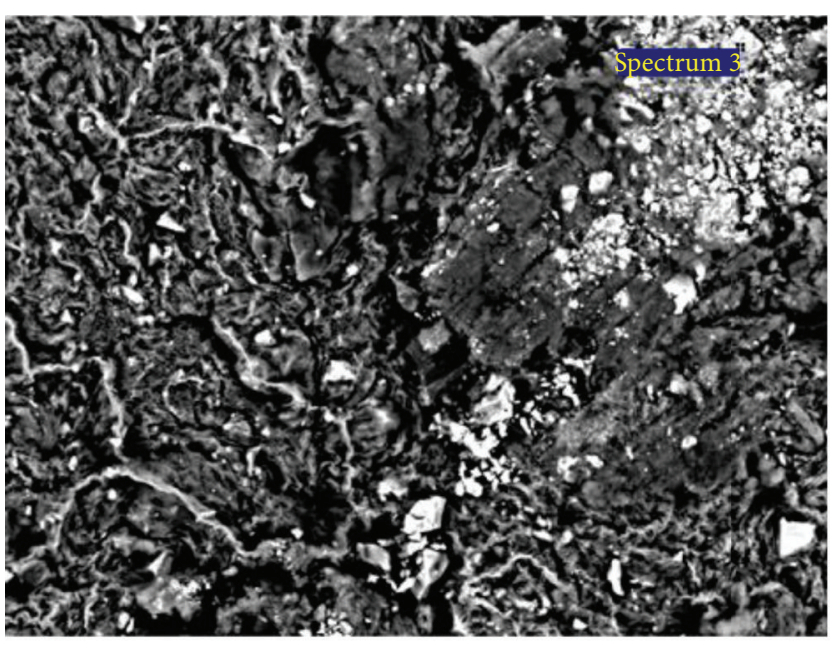

$100 \mu \mathrm{m}$

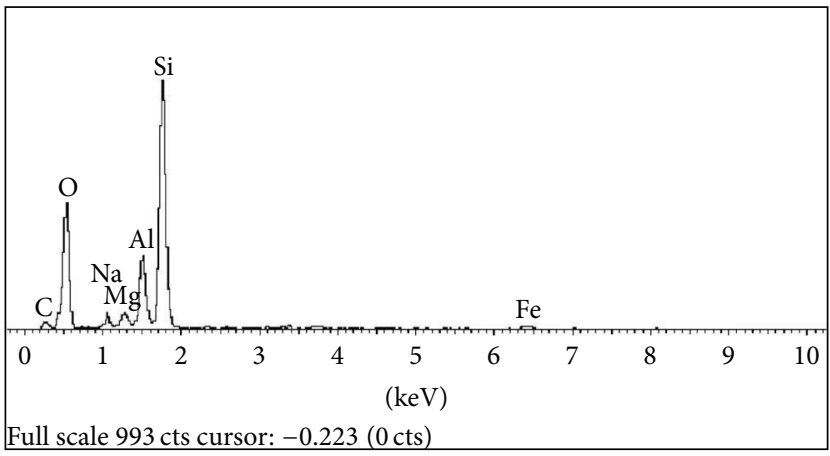

A-A

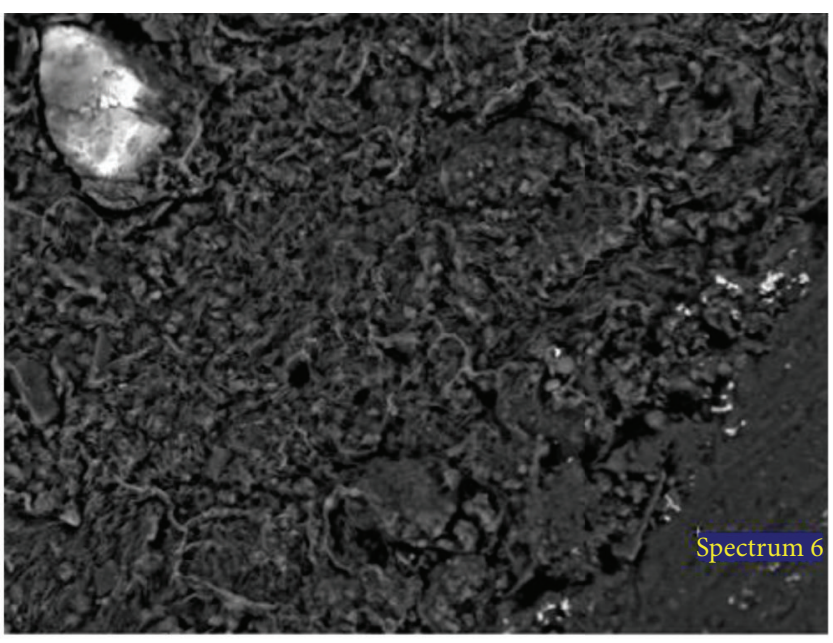

$100 \mu \mathrm{m}$

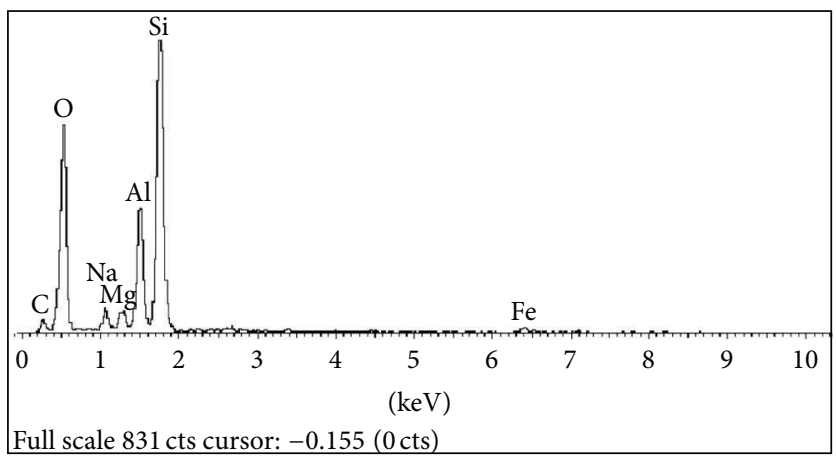

B-A

FIGURE 4: SEM-EDS images of the bentonite particles (A-A and B-A) hydrated with distilled water.

The structure of the bentonite particles after being hydrated with the $\mathrm{NaCl}$ solution is shown in images (A-S and B-S) (Figure 2). The morphological patterns, particle arrangements, and interactions seen in these two images are different from those observed in the previous SEM images. In comparison to distilled water hydration, as shown in A$\mathrm{A}$ and B-A (Figure 2), the bentonite particles in A-S and B-S (Figure 2) experienced less swelling. Consequently, it can be assumed that the $\mathrm{NaCl}$ solution is able to change the response of the bentonite particles.

In order to further examine the effect that hydration with other solutions had on both types of bentonite particles, an additional investigation of the bentonite particles was conducted using an energy-dispersive X-ray spectrometer (EDS). The element distribution within each sample was then determined.

Figure 3 shows the original elemental composition of bentonite in the two different GCL samples of bentonite powder and granular bentonite. Generally, bentonite particles contain elements, such as iron (Fe), aluminum ( $\mathrm{Al})$, and silicone $(\mathrm{Si})$, which may be carried along in the form of iron (III) oxide $\left(\mathrm{Fe}_{2} \mathrm{O}_{3}\right)$, aluminum oxide $\left(\mathrm{Al}_{2} \mathrm{O}_{3}\right)$, and silicates $\left(\mathrm{SiO}_{2}\right)$. Other minor elements of the alkali groups, including magnesium $(\mathrm{Mg})$, potassium $(\mathrm{K})$, and sodium $(\mathrm{Na})$, may also be found as constitutional elements of bentonite [33]. As seen in Figure 4, almost no diversion was observed in the elemental distribution of the particles when bentonite was hydrated with distilled water, since, in this case, $\mathrm{H}_{2} \mathrm{O}$ was the only additive in the mixture. At this stage, it should be noted that no moisture content was found in all of the samples after oven-drying.

Among all the elements found in bentonite, silicon, in the form of silicate, is the main component of this form of clay, followed by aluminum and oxygen. Despite the morphologic alteration of the bentonite particles, no change could be observed in the quantities of the dominant elements.

The elemental distribution of bentonite particles after hydration with the $100 \mathrm{mM}$ concentration of the $\mathrm{NaCl}$ solution is shown in Figure 5. Sodium chloride was absorbed by the bentonite, as indicated by the chlorine elements found during the EDS analysis. However, chlorine only appeared in a small area on the surface of the bentonite, which is highlighted as the brighter area in the graph (i.e., spectrum 4). Consequently, it was concluded that the bonding structure of the bentonite particles underwent only minor changes. This phenomenon was observed in both the granular and powder forms of bentonite. 


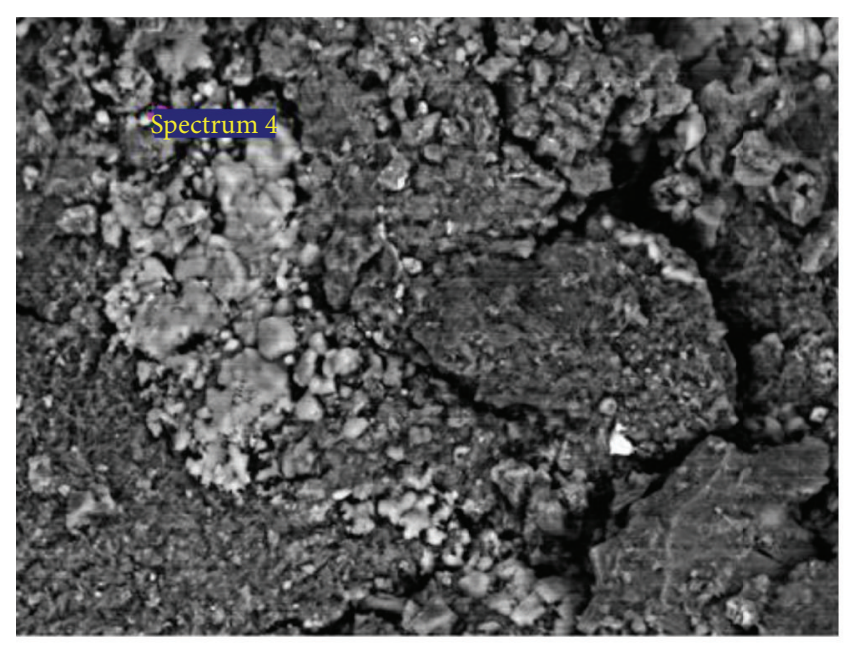

$100 \mu \mathrm{m}$

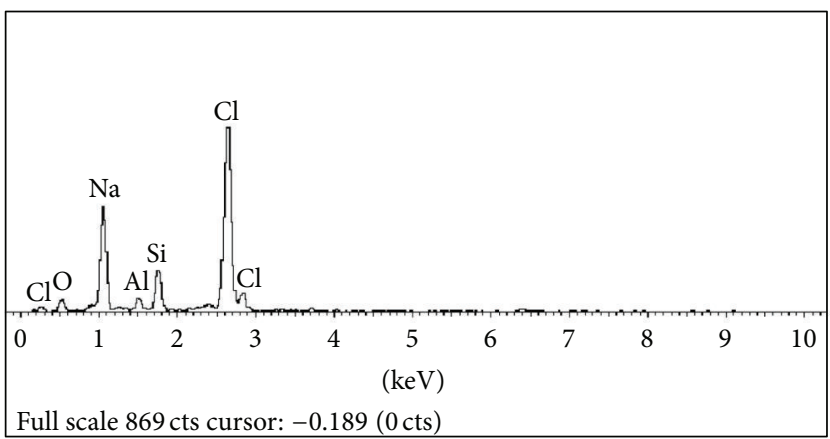

A-S

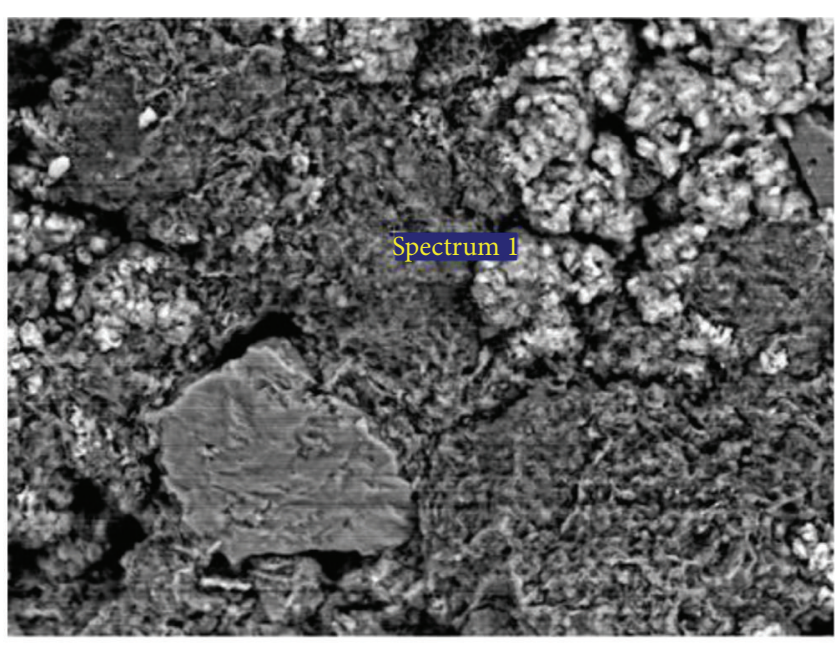

$100 \mu \mathrm{m}$

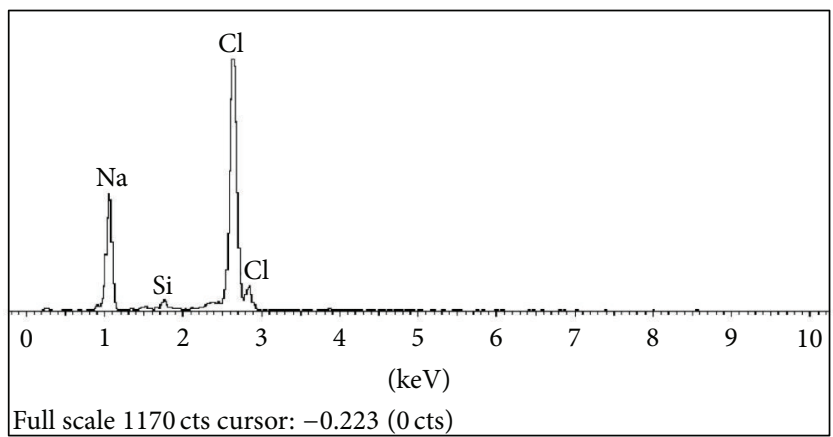

B-S

FIGURE 5: SEM-EDS images of the bentonite particles (A-S and B-S) hydrated with NaCl.

3.2. Effect of $\mathrm{NaCl}$ on Hydraulic Performance. The permeability of the bentonite layer, sandwiched between the geotextiles, changes with variations in the water quantity imposed on the bentonite surface [32]. Because GCLs are used as leachate barriers in landfill liners, the incompatibility of their permeability impacts their performance, and this is a major issue during the design stages of a landfill. Therefore, the hydraulic performance of GCLs when subjected to hydration using both types of permeant solutions, distilled water and $\mathrm{NaCl}$, was also assessed in this study. The results are illustrated in Figure 6.

As stated earlier, this present study also investigated the feasibility of using a GCL as an effective hydraulic barrier in the presence of $\mathrm{NaCl}$ in the permeating solution, so that the influence of the types of permeant solutions on a hydrated GCL could be established. It was found that the respective hydraulic conductivities of both GCL samples were $1.24 \times 10^{-11} \mathrm{~m} / \mathrm{sec}$ and $6.91 \times 10^{-11} \mathrm{~m} / \mathrm{sec}$. Furthermore, hydration with $\mathrm{NaCl}$ was observed to have slightly altered the permeability of the GCL, and an increase in the hydraulic conductivities was noted for both samples. As displayed in Figure 6 , the hydraulic conductivity of sample A-S jumped to $1.36 \times 10^{-10} \mathrm{~m} / \mathrm{sec}$, while the hydraulic conductivity of B-S increased to $1.98 \times 10^{-10} \mathrm{~m} / \mathrm{sec}$.

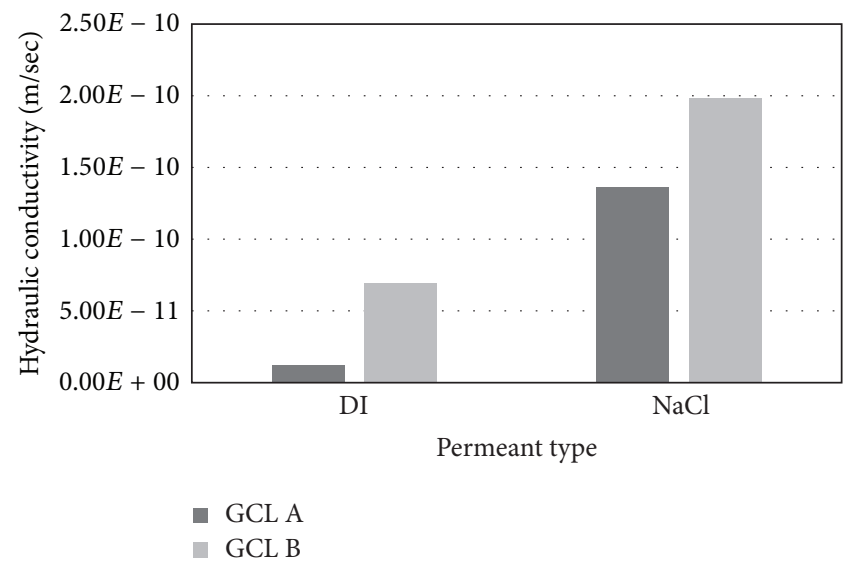

FIGURE 6: Hydraulic conductivity of the GCL samples after hydration with both distilled water (A-A, B-A) and $\mathrm{NaCl}$ (A-S, B-S).

\section{Conclusions}

Based on optical microscopic examination, distilled water hydration produced no changes in the GCL samples after drying. On the other hand, crystal deposits were found at both the bentonite surface and the geosynthetic cover when 
$100 \mathrm{mM} \mathrm{NaCL}$ was used as the hydration solution. Hydration of a GCL with both distilled water and $\mathrm{NaCL}$ resulted in alterations in the surface morphology of the bentonite particles. A trend was observed for the bentonite particles to approach/attach to each other after the samples were hydrated with distilled water. However, less swelling seemed to occur when the samples were hydrated with the $100 \mathrm{mM} \mathrm{NaCL}$ solution. The EDS images showed that silicon, aluminum, and iron were the main elements in both the granular and powder forms of bentonite. Sodium was present in the bentonite in the form of sodium oxide $\left(\mathrm{Na}_{2} \mathrm{O}\right)$. The bentonite surface area was found to contain chlorine after GCL hydration using an unevenly dispersed $\mathrm{NaCl}$ solution. The hydraulic conductivity of GCL also appeared to change under the influence of $\mathrm{NaCL}$ hydration. When the GCL samples containing either granular bentonite or bentonite powder were hydrated using the $\mathrm{NaCl}$ solution, their hydraulic conductivity tended to increase.

\section{Competing Interests}

The author declares that there is no conflict of interests regarding the publication of this paper.

\section{Acknowledgments}

The author acknowledges the use of Curtin University's Microscopy \& Microanalysis Facility, whose instrumentation has been partially funded by Curtin University and the State and Commonwealth Governments.

\section{References}

[1] T. H. Christensen, R. Cossu, and R. Stegmann, Sanitary Landfilling: Process, Technology and Environmental Impact, Academic Press, London, UK, 2012.

[2] C. Ludwig, S. Hellweg, and S. Stucki, Municipal Solid Waste Management, Springer, Berlin, Germany, 2002.

[3] X. B. Feng, S. L. Tang, Z. G. Li, S. F. Wang, and L. Liang, "Landfill is an important atmospheric mercury emission source," Chinese Science Bulletin, vol. 49, no. 19, pp. 2068-2072, 2004.

[4] G. Tchobanoglous, H. Theisen, and S. Vigil, Integrated Solid Waste Management: Engineering Principles and Management Issues, McGraw-Hill, New York, NY, USA, 1993.

[5] M. Z. Justin and M. Zupančič, "Combined purification and reuse of landfill leachate by constructed wetland and irrigation of grass and willows," Desalination, vol. 246, no. 1-3, pp. 157-168, 2009.

[6] Z. Daud, H. A. Aziz, M. N. Adlan, and Y.-T. Hung, "Application of combined filtration and coagulation for semi-aerobic leachate treatment," International Journal of Environment and Waste Management, vol. 4, no. 3-4, pp. 457-469, 2009.

[7] S. Mohajeri, H. A. Aziz, M. H. Isa, M. A. Zahed, and M. N. Adlan, "Statistical optimization of process parameters for landfill leachate treatment using electro-Fenton technique," Journal of Hazardous Materials, vol. 176, no. 1-3, pp. 749-758, 2010.

[8] W. Li, Q. Zhou, and T. Hua, "Removal of organic matter from landfill leachate by advanced oxidation processes: a review,"
International Journal of Chemical Engineering, vol. 2010, Article ID 270532, 10 pages, 2010.

[9] A. A. Foul, H. A. Aziz, M. H. Isa, and Y.-T. Hung, "Primary treatment of anaerobic landfill leachate using activated carbon and limestone: batch and column studies," International Journal of Environment and Waste Management, vol. 4, no. 3-4, pp. 282298, 2009.

[10] P. Palaniandy, M. N. Adlan, H. A. Aziz, and M. F. Murshed, "Application of dissolved air flotation (DAF) in semi-aerobic leachate treatment," Chemical Engineering Journal, vol. 157, no. 2-3, pp. 316-322, 2010.

[11] S. Renou, J. G. Givaudan, S. Poulain, F. Dirassouyan, and P. Moulin, "Landfill leachate treatment: review and opportunity," Journal of Hazardous Materials, vol. 150, no. 3, pp. 468-493, 2008.

[12] Z. Yang and S. Zhou, "The biological treatment of landfill leachate using a simultaneous aerobic and anaerobic (SAA) bio-reactor system," Chemosphere, vol. 72, no. 11, pp. 1751-1756, 2008.

[13] M. Bodzek, J. Surmacz-Górska, and Y. Hung, "Treatment of landfill leachate," in Handbook of Industrial and Hazardous Wastes Treatment, L. Wang, Y. Hung, and C. Yapijakis, Eds., Marcel Dekker, New York, NY, USA, 2004.

[14] M. Isidori, M. Lavorgna, A. Nardelli, and A. Parrella, “Toxicity identification evaluation of leachates from municipal solid waste landfills: a multispecies approach," Chemosphere, vol. 52, no. 1, pp. 85-94, 2003.

[15] E. Benfenati, E. Porazzi, R. Bagnati et al., "Organic tracers identification as a convenient strategy in industrial landfills monitoring," Chemosphere, vol. 51, no. 8, pp. 677-683, 2003.

[16] Y. Chen, D. Gao, B. Zhu, and R. Chen, "Seismic stability and permanent displacement of landfill along liners," Science in China, Series E: Technological Sciences, vol. 51, no. 4, pp. 407423, 2008.

[17] T.-J. Hu, G.-M. Zeng, and X.-Z. Yuan, "Decision-making mode of integrated disposal scheme for regional municipal solid waste," Journal of Hunan University Natural Sciences, vol. 29, no. 2, pp. 79-87, 2002.

[18] J. Kalka, "Landfill leachate toxicity removal in combined treatment with municipal wastewater," The Scientific World Journal, vol. 2012, Article ID 202897, 7 pages, 2012.

[19] Y.-J. Du, S.-L. Shen, S.-Y. Liu, and S. Hayashi, "Contaminant mitigating performance of Chinese standard municipal solid waste landfill liner systems," Geotextiles and Geomembranes, vol. 27, no. 3, pp. 232-239, 2009.

[20] K. Widziewicz, J. Kalka, M. Skonieczna, and P. Madej, “The comet assay for the evaluation of genotoxic potential of landfill leachate," The Scientific World Journal, vol. 2012, Article ID 435239, 8 pages, 2012.

[21] L. Changli, Z. Feng-E, Z. Yun et al., "Experimental and numerical study of pollution process in an aquifer in relation to a garbage dump field," Environmental Geology, vol. 48, no. 8, pp. 1107-1115, 2005.

[22] N. Yesiller and C. D. Shackelford, "Geoenvironmental engineering," in Geotechnical Engineering Handbook, B. M. Das, Ed., chapter 13, J. Ross Publishing, Fort Lauderdale, Fla, USA, 2010.

[23] F. Jingjing, "Leakage performance of the GM + CCL liner system for the MSW landfill," The Scientific World Journal, vol. 2014, Article ID 251465, 9 pages, 2014.

[24] A. Thammathiwat and W. Chim-oye, "Effect of permeant liquid on the swell volume and permeability of geosynthetic clay 
liners," Electronic Journal of Geotechnical Engineering, vol. 15, pp. 1183-1197, 2010.

[25] C. B. Lake and R. K. Rowe, "Swelling characteristics of needlepunched, thermally treated geosysnthetic clay liners," Geotextiles and Geomembranes, vol. 18, no. 2-4, pp. 77-101, 2000.

[26] A. Barclay and M. T. Rayhani, "Effect of temperature on hydration of geosynthetic clay liners in landfills," Waste Management \& Research, vol. 31, no. 3, pp. 265-272, 2013.

[27] J. Bowders, Geosynthetic Clay Liners for Waste Containment Facilities, CRC Press, Leiden, The Netherlands, 2010.

[28] D. C. Kolstad, C. H. Benson, and T. B. Edil, "Hydraulic conductivity and swell of non prehydrated geosynthetic clay liners permeated with multispecies inorganic solutions," Journal of Geotechnical and Geoenvironmental Engineering, vol. 130, no. 12, pp. 1236-1249, 2004.

[29] R. J. Petrov and R. K. Rowe, "Geosynthetic clay liner (GCL) chemical compatibility by hydraulic conductivity testing and factors impacting its performance," Canadian Geotechnical Journal, vol. 34, no. 6, pp. 863-885, 1997.

[30] Q. Xue, Q. Zhang, and L. Liu, "Impact of high concentration solutions on hydraulic properties of geosynthetic clay liner materials," Materials, vol. 5, no. 11, pp. 2326-2341, 2012.

[31] W. P. Gates, P. Hines, and A. Bouazza, "SEM study of mineralogical changes to GCLs following permeation by strongly alkaline leachates," in Geo-Frontiers 2011: Advances in Geotechnical Engineering, pp. 2021-2030, ASCE, 2011.

[32] H. Y. Jo, C. H. Benson, and T. B. Edil, "Hydraulic conductivity and cation exchange in non-prehydrated and prehydrated bentonite permeated with weak inorganic salt solutions," Clays and Clay Minerals, vol. 52, no. 6, pp. 661-679, 2004.

[33] W. A. Allo and H. H. Murray, "Mineralogy, chemistry and potential applications of a white bentonite in San Juan province, Argentina," Applied Clay Science, vol. 25, no. 3-4, pp. 237-243, 2004. 

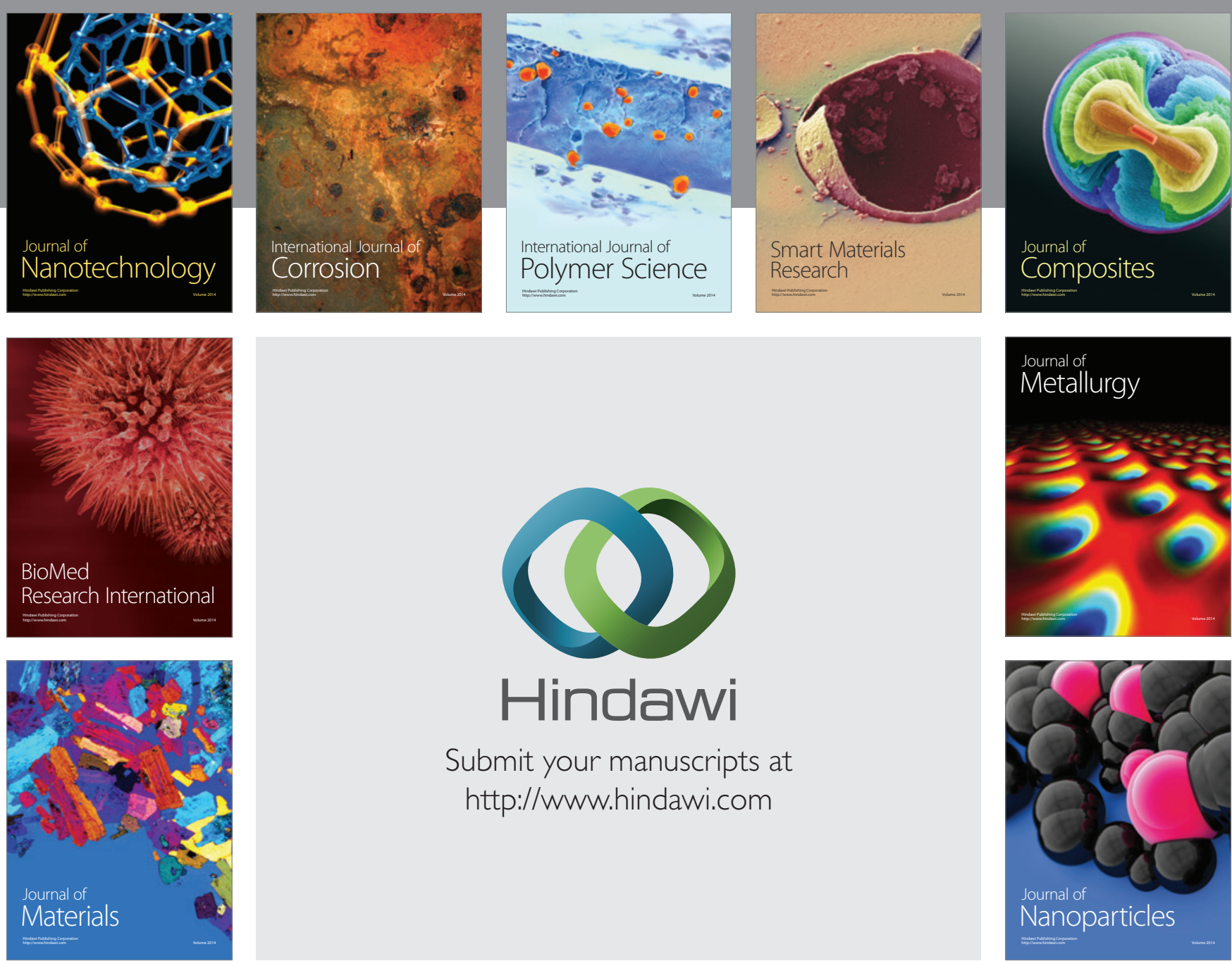

\section{Hindawi}

Submit your manuscripts at

http://www.hindawi.com

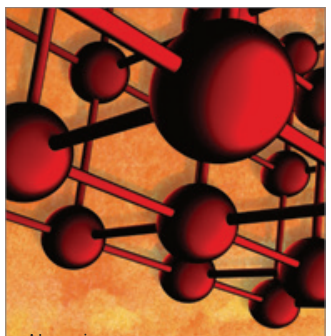

Materials Science and Engineering
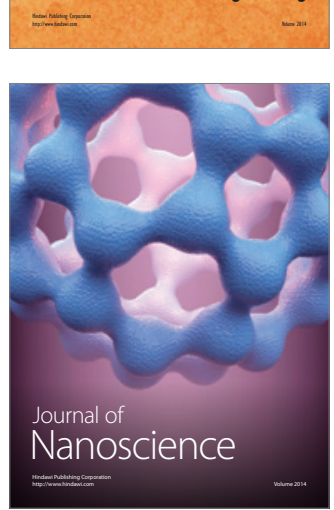
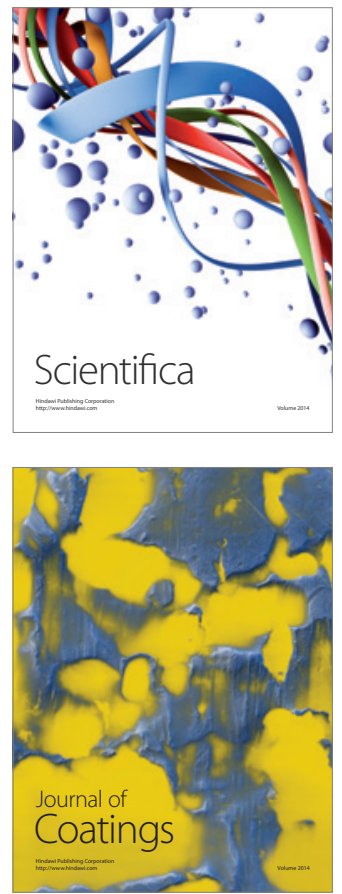
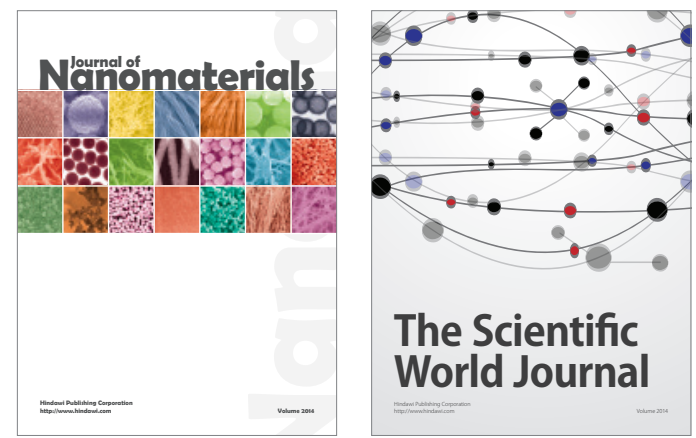

The Scientific World Journal
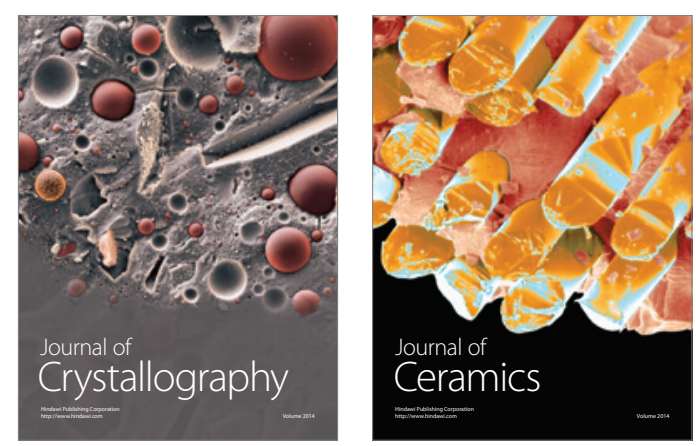
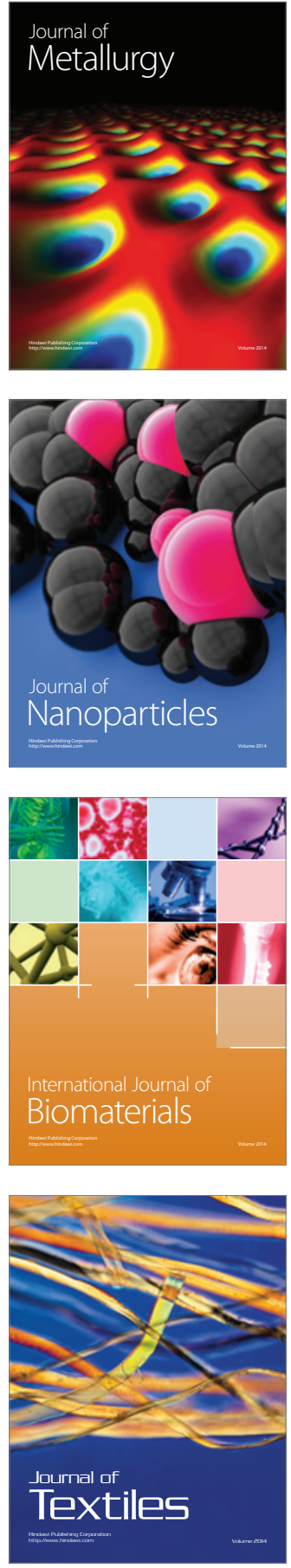